\title{
Post-Abortion Endometritis
}

National Cancer Institute

\section{Source}

National Cancer Institute. Post-Abortion Endometritis. NCI Thesaurus. Code C142885.

Endometritis that develops following an abortion. 